Int. J. Curr. Res. Med. Sci. (2017). 3(8): 71-77

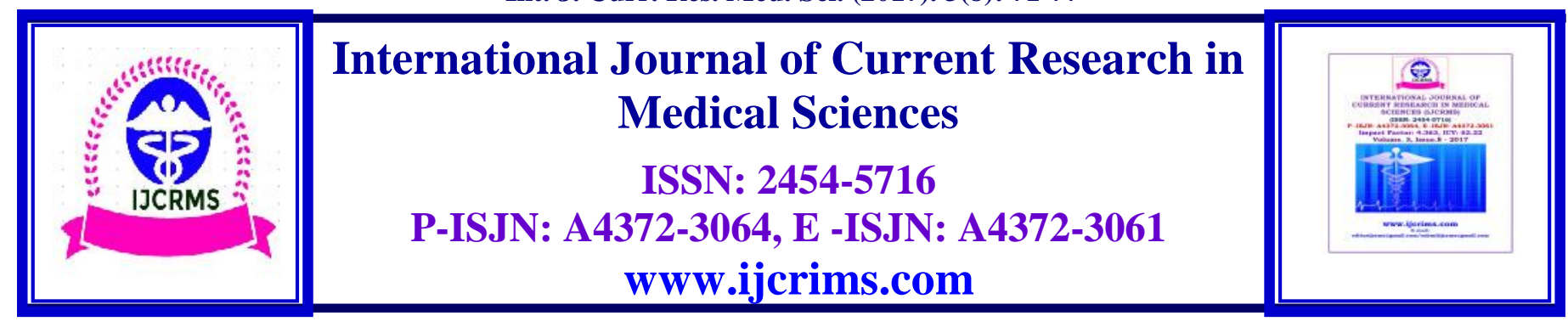

\title{
Etiology, risk factors and outcome of acute non-variceal bleed in hospitalised patients - A cross sectional study.
}

\author{
Seena Sankar ${ }^{1 *}$, Shruthi Kulkarni ${ }^{2}$, Anu Desai ${ }^{3}$ \\ ${ }^{1}$ Professor, Department of Medicine, St.John's Medical College Hospital, Bangalore-34 \\ ${ }^{2}$ Assistant Professor, Department of Medicine, St.John's Medical College Hospital, Bangalore-34 \\ ${ }^{3}$ Senior Resident, Department of Medicine, St.John's Medical College Hospital, Bangalore-34 \\ *Corresponding author: Shruthi Kulkarni, \\ Assistant Professor, Department of Medicine, St.John's Medical College Hospital, \\ Sarjapur road, Bangalore-34 \\ E-mail: shruthi.mk@stjohns.in
}

\begin{abstract}
Introduction: Upper gastrointestinal bleeding (UGIB) is a common presentation to emergency departments with an incidence of approximately 45-172 per 100000 people per year. ${ }^{\mathbf{1 - 3}}$ Despite recent advances in diagnosis and therapy, there is a lack of improvement in the mortality resulting from bleeding peptic ulcers. Therefore, we conducted this study to enumerate the various causes and risk factors of acute non-variceal bleed (NVB) and predict outcome (rebleeding and mortality) using the Rockall score ${ }^{4}$.

Methods: We conducted a cross sectional study on patients admitted with acute non-variceal bleed (NVB) to St.John's Medical College Hospital. All patients underwent an endoscopy within 24 hours of presentation. We studied the etiologies, risk factors of acute NVB and risk stratified patients according to Rockall score ${ }^{4}$. The outcome (rebleeding and mortality) were assessed based on the Rockall score.

Results: We screened 200 patients with acute UGIB and studied 63 patients with acute NVB for causes and outcome. We had more non-variceal bleeds in elderly population $36(57 \%)$ as compared to younger population 27 (43\%). Twenty five (40\%) patients were on drugs which predispose them to upper GI bleed. The most commonly used drugs were aspirin (18.0\%) followed by NSAIDs (10.5\%). Causes of non variceal bleed were gastric erosions $21(33 \%)$, duodenal ulcer 21 (33\%) followed by gastric ulcer 12 (19\%). The patients with a Rockall score of $<4$ had a statistically significant lesser complications as compared to those with a score $\mathrm{p}<0.001$.

Conclusion: Almost half of the patients were on medications that predispose them to upper GI bleed, common drug being aspirin. This is one of the few studies which evaluated the role of commonly used antidepressants. The complete Rockall score can be used to predict adverse outcomes like re-bleeding and mortality, which can be utilized to identify high risk patients for close monitoring to prevent complications.
\end{abstract}

Keywords: Acute upper GI bleed, non variceal bleed, risk factors, Rockall score, outcome 


\section{Introduction}

Acute upper gastrointestinal (UGI) hemorrhage is one of the commonest causes for hospitalization worldwide. UGIB is also a major healthcare expense and is the most frequent gastrointestinal reason for admission to hospital. ${ }^{1-3}$ Mortality rates, while high appear to be declining in recent years. Data from the UK show a mortality rate of $14 \%$ in $(1995)^{1}$ with a reduction to $7 \%$ in 2007. The low mortality rates have been attributed to close monitoring of patients, prompt application of endoscopic haemostasis which reduces rebleeding and emergency surgery in patients with peptic ulcer bleeding and variceal bleeds. Consequently there are lower mortality rates due to surgical complications or coexisting diseases. ${ }^{5}$ However, mortality rates have wide geographic variability.

There are various causes of UGI bleed described from gastric and duodenal ulcers to pancreatic disease and neoplasm along with its predisposing factors. ${ }^{6}$ Aging itself may result in various physiologic changes in the gastrointestinal tract ${ }^{7}$, which may increase the risk for the development of acid-related disorders. There is an increased incidence of acid-related bleeding with increasing age. ${ }^{8-10}$ Also there is an increased usage of gastro duodenal-damaging drugs, including aspirin, clopidogrel, and NSAIDs which is 2 times greater in elderly than the young population. Use of antiplatelet agents causes impaired hemostasis due to platelet dysfunction and can affect healing of peptic ulcers. ${ }^{11}$ The most frequently reported factors for acute non-variceal bleed (NVB) included old age, presence of significant comorbidity including cardiac disease, liver and renal failure, disseminated malignancy, presentation with shock (in terms of low systolic blood pressure or tachycardia), in-hospital bleeding, low hemoglobin, diagnosis at endoscopy, presence of stigmata of recent hemorrhage $(\mathrm{SRH})^{5}$, and development of rebleeding.

The two most adverse outcomes associated with upper GI bleed are mortality and rebleeding. Over the years, various scores have been devised to calculate the potential risk and predictability of the above outcomes. ${ }^{4,12}$ The Complete Rockall score ${ }^{4}$ which includes both pre endoscopic and endoscopic parameters can predict rebleed and mortality. The Rockall score has been traditionally used to evaluate non variceal bleeds. It is used to broadly categorise patients by risk and has concluded that the risk of rebleeding as well as the risk of death increases as the risk score increases; secondly, that patients who re-bleed have an increased mortality compared with those who do not re-bleed.

Despite recent advances in diagnosis and therapy, there is a lack of improvement in the mortality resulting from bleeding peptic ulcers. UGIB is also a major healthcare expense and is the most frequent gastrointestinal reason for admission to hospital. ${ }^{1-3}$ There is very limited recent Indian data available on upper GIT bleeding which continues to have a high incidence and a high mortality rate despite advances in pharmacotherapy and diagnostic modalities. Therefore, we conducted this study to enumerate the various causes and risk factors of acute NVB and predict outcome (re-bleeding and mortality) using the Rockall score.

\section{Materials and Methods}

We conducted a cross sectional study on patients admitted to St.John's Medical College Hospital. We screened 200 patients, aged 18 years and above presenting with symptoms of UGI bleed (first/any episode of bleeding, within 7 days) to the department of Medicine /Gastroenterology. Patients with trauma/ road traffic accidents were excluded. Patients underwent an endoscopy within 24 hours of presentation and those with variceal bleeding were further excluded from the study. We collected data on demographic variables, co-morbidities and risk factors for UGI bleed. We followed up the patient till discharge. The presence of hemodynamic instability was defined as: systolic blood pressure $<100 \mathrm{mmHg}$, heart rate $>100$ beats/min and/or orthostatic changes in systolic blood pressure (a decrease of $>10 \%$ ) or heart rate (an increase of >10\%) between a supine and seated position ${ }^{11}$. We studied the etiologies of acute non variceal bleed (NVB), risk factors and risk stratified patients 
according to Rockall score. ${ }^{4}$ The outcome were assessed based on the following parameters: rebleeding episodes as defined by the Baveno criteria 13, requirement of blood transfusion, duration of hospital stay and mortality.

Baveno criteria for rebleeding ${ }^{13}$ includes:

- Recurrence of bleeding after the first $24 \mathrm{~h}$ and within 5 days of admission as

The Rockall scoring system ${ }^{4}$ evidenced by new melaena or hematemesis

- Requirement for $>2$ units of PRBCs in a 24-h time period

- Hemodynamic instability

\begin{tabular}{|c|c|c|c|c|}
\hline The & all Risk Sconing System & & & \\
\hline \multirow[b]{2}{*}{ Variable } & \multicolumn{4}{|c|}{ Score } \\
\hline & 0 & 1 & 2 & 3 \\
\hline Age & $<60 \mathrm{yr}$ & $60-79 \mathrm{yr}$ & $\geq 80 \mathrm{yr}$ & \\
\hline \multirow[t]{4}{*}{ Shock } & "No shock" & "Tachycardia" & "Hypotension" & \\
\hline & Systolic BP & Systolic BP & Systolic BP & \\
\hline & $>100$ pulse & $>100$ pulse & $<100$ & \\
\hline & $<100$ & $>100$ & & \\
\hline Comorbidity & No major comorbidity & & $\begin{array}{l}\text { Cardiac failure, IHD, any } \\
\text { major comorbidity }\end{array}$ & $\begin{array}{l}\text { Renal failure, liver } \\
\text { failure, disseminated } \\
\text { malignancy }\end{array}$ \\
\hline Diagnosis & $\begin{array}{l}\text { Mallory-Weiss tear, no } \\
\text { lesion identified, no } \\
\text { SRH }\end{array}$ & All other diagnoses & $\begin{array}{l}\text { Malignancy of upper GI } \\
\text { tract }\end{array}$ & \\
\hline Major SRH & None or dark spot only & & $\begin{array}{l}\text { Blood in upper GI tract, } \\
\text { adherent clot, visible or } \\
\text { spurting vessel }\end{array}$ & \\
\hline
\end{tabular}

\section{Statistical analysis}

SPSS version 16 was the software used to analyze data. Descriptive variables are represented as percentage and frequencies. Continuous variables are represented as mean and standard deviation. A Chi square test was done to find the difference between the Rockall score and outcomes.

\section{Results}

We screened two hundred patients admitted to St John's Medical College Hospital with upper GI bleed. Out of the 200 patients who underwent endoscopy 97 (48\%) patients had varices, 63 (32\%) patients had non variceal bleed and 22 (11\%) patients had both. Endoscopy was normal in $18(9 \%)$ patients. Out of 63 patients with nonvariceal bleed, the mean age of the study population was 48.8 (15.3) years. We had more non-variceal bleeds in elderly population 36 (57\%) as compared to younger population 27 $(43 \%)$.

Forty seven (75\%) were males and $16(25 \%)$ were females. The mean duration of hospital stay was 6.44(SD3.59) days. The mean haemoglobin in our study population was 9.95 (SD 2.89) gm/dl. The mean platelet count in lakhs/cumm was 1.5 (SD $0.88)$.

Majority of the patients, 33 (52\%) presented with both hematemesis and malena. 21 patients $(33.5 \%)$ patients out of 63 presented with hematemesis alone. Nine $(14.5 \%)$ patients had only malena. Twenty eight $(45 \%)$ patients had hemodynamic instability with 28 patients $(44.5 \%)$ having tachycardia and 20 patients $(31 \%)$ had hypotension. 
Twenty five (40\%) patients were on drugs which predispose them to upper GI bleed. The most commonly used drugs were aspirin (18.0\%) followed by NSAIDs $(10.5 \%)$. 4 patients were HBV (2 patients) and HCV (2 patients) chronic carriers.

The most common co-morbidities were osteoarthritis 12(19\%), diabetes mellitus 9(14\%), malignancy $8(12 \%)$, depression $7(11 \%)$ and IHD $6(10 \%) .24$ patients had multiple co-morbidities.

Causes of non-variceal bleed were gastric erosions 21(33\%), duodenal ulcer 21(33\%) followed by gastric ulcer $12(19 \%)$. Other causes included 1 malignancy, 1 surgical leak, 1 petechial hemorrhage, 1 hemosuccus pancreaticus, 4 Mallory Weiss and 1 vascular lesion.
Risk factors evaluated included alcohol and medications. 14(22\%) patients had history of significant alcohol intake. Twenty nine (46\%) patients were on medications. 12(19\%) patients were on aspirin, $6(9 \%)$ on NSAIDS, $4(6 \%)$ on steroids, $3(5 \%)$ on anticoagulants, $2(3 \%)$ on antidepressants and $2(3 \%)$ patients on multiple medications.

We compared each of the Rockall score to the predefined outcomes of the study, which were rebleeding, mortality or an uneventful discharge (table 1). We then chose a cut off point of 4 based on the study by Lahiff et al. ${ }^{3}$ Based on the cut-off point of $4,11(17.5 \%)$ patients had re-bleed, $46(73 \%)$ patients were discharged without any untoward incidents during the hospital stay and $6(9.5 \%)$ patients died. The patients with a Rockall score of $<4$ had statistically significant lesser complications as compared to those with a score $\mathrm{p}<0.001$ (table 2).

Table 1: Individual Rockall score and outcomes

\begin{tabular}{|c|c|c|c|c|c|c|c|c|c|}
\hline & \multicolumn{9}{|c|}{ Individual Rockall Score for Non-Variceal Bleeds } \\
\hline & 0 & 1 & 2 & $\mathbf{3}$ & 4 & 5 & 6 & 7 & $\geq 8$ \\
\hline $\mathrm{N}(\%)$ & $\begin{array}{c}1 \\
(1.1)\end{array}$ & $\begin{array}{c}8 \\
(9.4)\end{array}$ & $\begin{array}{c}9 \\
(10.5)\end{array}$ & $\begin{array}{c}14 \\
(16.4)\end{array}$ & $\begin{array}{c}10 \\
(11.7)\end{array}$ & $\begin{array}{c}15 \\
(17.6)\end{array}$ & $\begin{array}{c}13 \\
(15.2)\end{array}$ & $\begin{array}{c}4 \\
(4.7)\end{array}$ & $\begin{array}{c}11 \\
(12.9)\end{array}$ \\
\hline $\begin{array}{c}\text { Rebleed } \\
\mathrm{N}(\%)\end{array}$ & 0 & 0 & $\begin{array}{c}2 \\
(22.2)\end{array}$ & $\begin{array}{c}1 \\
(7.1)\end{array}$ & 0 & $\begin{array}{c}1 \\
(6.6)\end{array}$ & $\begin{array}{c}6 \\
(46.1)\end{array}$ & $\begin{array}{c}1 \\
(25)\end{array}$ & $\begin{array}{c}5 \\
(45.4)\end{array}$ \\
\hline $\begin{array}{l}\text { Mortality } \\
\mathrm{N}(\%)\end{array}$ & 0 & 0 & 0 & $\begin{array}{c}1 \\
(7.1)\end{array}$ & $\begin{array}{c}1 \\
(10)\end{array}$ & $\begin{array}{c}1 \\
(6.6)\end{array}$ & 0 & 0 & $\begin{array}{c}3 \\
(27.2)\end{array}$ \\
\hline
\end{tabular}

Table 2: Rockall score and outcomes

\begin{tabular}{|c|c|c|c|c|c|}
\hline & & \multicolumn{2}{|c|}{ Rockall Score } & & \multirow{2}{*}{ p-value } \\
\hline \multirow{4}{*}{ Outcomes } & & $\geq 4$ & $<4$ & Total & p-e \\
\cline { 2 - 5 } & Re-bleed & $8(72.7 \%)$ & $3(27.3 \%)$ & $11(17.5 \%)$ & \\
\cline { 2 - 5 } & Mortality & $5(83.3 \%)$ & $1(16.7 \%)$ & $6(9.5 \%)$ & \multirow{2}{*}{$<0.001$} \\
\cline { 2 - 5 } & Discharge & $34(74 \%)$ & $12(26 \%)$ & $46(73 \%)$ & \\
\hline \multicolumn{2}{|c|}{ Total } & $47(74.6 \%)$ & $16(25.4 \%)$ & $63(100 \%)$ & \\
\hline
\end{tabular}


All patients received Proton Pump Inhibitors (PPI). Actively bleeding duodenal and gastric ulcers were treated with local adrenaline injections. Follow up in hospital, till discharge showed that $30(50 \%)$ patients among 63 received blood transfusion and 11 of them had re-bleeding. The mean blood transfusion received was 1.9(SD1.18) units.

The mean Rockall score was 4.5(SD2.1).

\section{Discussion}

Upper gastrointestinal bleeding is one of the common causes of acute and critical admissions in clinical practice. We conducted this study to offer insight on the current scenario of non variceal bleed, enumerate risk factors and response to treatment.

In our study, majority of the patients were males. This data is compatible with that of various international studies. ${ }^{\mathbf{5 , 1 4}}$ This could be attributed to higher rates of alcoholism and smoking amongst the male population which are important risk factors for UGIB. Male gender is also a known risk factor for adverse outcomes like rebleeding and mortality. Alternatively this could be due to the small sample size or may indicate that a lower proportion of female patients report to the hospital or have access to hospital in India.

The 4 patients in the non variceal group who had $\mathrm{HBV}$ and HCV infection were chronic carriers with no evidence of chronic liver disease. The source of bleeding was incidentally associated duodenal ulcers. There is paucity of data studying correlations between viral infections and GI bleeds.

NSAIDs and anti-platelet therapy are known risk factors for peptic ulcer bleeds and erosions. They impair hemostasis by causing platelet dysfunction and adversely affect the ulcer healing process. ${ }^{11}$ In our study, $46 \%$ of the patients were on drugs which predispose them to upper GI bleed. The most commonly used drugs were aspirin (19.0\%) followed by NSAIDs (9\%) as also shown in other studies. 11, 15 In our study, 2 patients were on antidepressants (Escitalopram and sertaline). In a pharmacovigilance study using data from 127,504 individuals, commonly prescribed high-serotonin transporter affinity antidepressants such as paroxetine, duloxetine, escitalopram and sertaline were found to have significantly elevated risk for UGIB and stroke as compared to low serotonin transporter affinity antidepressants like bupropion and mirtazapine. The reason for this needs further evaluation. $^{16}$

24 patients had multiple co-morbidities in our study. These comorbidities were defined as those included in the Rockall scoring system (i.e. cardiac failure, ischemic heart disease, renal or liver disease and metastatic cancer). Nongastrointestinal comorbidity is an independent risk factor for GIB, and contributes to a greater proportion of patients with bleeding in the population than other recognized risk factors. 17 The various etiologies (endoscopic diagnosis) of acute NVB in our study are given in table 3. Our study showed lower incidence of duodenal ulcers and vascular lesions and varying incidence of other etiology as compared to other studies. This is probably because of wide differences in demography, medical seeking behavior, awareness and medical practices in different geographic areas.

The mean hemoglobin ( $\mathrm{Hb})$ in our study population was $9.95 \mathrm{gm} / \mathrm{dl}$. Comparison between hemoglobin values and outcome suggests a strong association between low $\mathrm{Hb}$ levels and poor outcome. $^{18}$

The Complete Rockall score which includes both pre endoscopic and endoscopic parameters can predict re-bleed and mortality. The Rockall score has been traditionally used to evaluate non variceal bleeds. The mean Rockall score in our study was 4.5050 (SD 2.1). A Rockall score of or more was found to be statistically significant in predicting re-bleeding and mortality with a $\mathrm{p}$ value of $<0.001$. These results are comparable with the other studies. ${ }^{4,15}$ 
Int. J. Curr. Res. Med. Sci. (2017). 3(8): 71-77

Table 3: Comparison of the SJMC study with international studies

\begin{tabular}{|c|c|c|c|c|c|c|}
\hline Etiology & $\begin{array}{c}\text { T.H.S.G } \\
\text { Rao } \\
{\text { et } \mathbf{a l}^{26}}^{(1976-89)}\end{array}$ & $\begin{array}{c}\text { Blatchford et } \\
\mathbf{a l}^{27} \\
(1997)\end{array}$ & $\begin{array}{c}\text { Thomopoulos } \\
\text { et al }^{13} \\
(\mathbf{2 0 0 0})\end{array}$ & $\begin{array}{l}\text { Di Fiore et } \\
\text { al }^{13} \\
(1996-2000)\end{array}$ & $\begin{array}{c}\text { Ahmed } \\
\text { et } \text { al }^{21} \\
(2004- \\
11)\end{array}$ & $\begin{array}{l}\text { SJMC } \\
\text { Study } \\
(2012- \\
2013)\end{array}$ \\
\hline $\begin{array}{l}\text { Total no. of } \\
\text { cases }\end{array}$ & 1480 & 1882 & 636 & 453 & 1000 & 200 \\
\hline Peptic ulcer & - & - & $59 \%$ & $31.1 \%$ & $28 \%$ & \\
\hline $\begin{array}{l}\text { Duodenal } \\
\text { ulcer }\end{array}$ & $24 \%$ & $16.95 \%$ & $33.3 \%$ & - & - & $10 \%$ \\
\hline Gastric ulcer & $4 \%$ & $10.6 \%$ & $19.2 \%$ & - & - & $6 \%$ \\
\hline Gastritis & - & $4.0 \%$ & - & $6.7 \%$ & $3 \%$ & \\
\hline Erosions & $9 \%$ & $6.23 \%$ & $7.2 \%$ & $9.5 \%$ & $5 \%$ & $10 \%$ \\
\hline Varices & $51 \%$ & $5.68 \%$ & $13.2 \%$ & $20.3 \%$ & $33 \%$ & $48 \%$ \\
\hline Tumours & - & $1.91 \%$ & $3.0 \%$ & $2.4 \%$ & $2.4 \%$ & $.02 \%$ \\
\hline $\begin{array}{l}\text { Mallory- } \\
\text { Weiss tear }\end{array}$ & - & $6.64 \%$ & $4.9 \%$ & $8.4 \%$ & $2 \%$ & $3.5 \%$ \\
\hline Oesophagitis & - & $20.63 \%$ & $1.3 \%$ & $10.8 \%$ & $8 \%$ & \\
\hline $\begin{array}{l}\text { Vascular } \\
\text { lesions }\end{array}$ & - & - & $0.9 \%$ & - & $4 \%$ & $.01 \%$ \\
\hline Others & $12 \%$ & $28.95 \%$ & $10.6 \%$ & $10.8 \%$ & $19 \%$ & $22.5 \%$ \\
\hline $\begin{array}{l}\text { Region of } \\
\text { study }\end{array}$ & India & Scotland & Greece & France & Egypt & India \\
\hline
\end{tabular}

The limitations of our study were - the relationship between the risk factors and upper GI bleed in terms of duration and dosage was not studied. The role of H. pylori in upper GI bleed was not elucidated and there was no follow up post discharge. Patients with high Rockall scores at the time of admission can have high rates of rebleeding and mortality after discharge at day 30 and would require a close follow up, an extended study period is essential to verify the same.

In conclusion, non-variceal bleeds are more frequent in elderly population as compared to younger population. There is a male preponderance. Almost half of the patients were on medications that predispose them to upper GI bleed, common drug being aspirin. This is one of the few studies which evaluated the role of commonly used antidepressants along with other well known gastro toxic agents like anti-platelets as risk factors for upper GI bleeds. The complete Rockall score can be used to predict adverse outcomes like rebleeding and mortality, which can be utilized to identify high risk patients for close monitoring to prevent complications.

\section{References}

1. Rockall TA, Logan RF, Devlin HB, Northfield TC. Incidence of and mortality from acute upper gastrointestinal haemorrhage in the United Kingdom. Steering Committee and members of the National Audit of Acute Upper Gastrointestinal Haemorrhage. BMJ 1995; 311:222-226.

2. Blatchford O, Davidson LA, Murray WR, Blatchford M, Pell J. Acute upper gastrointestinal haemorrhage in west of Scotland: case ascertainment study.BMJ 1997; 315:510-514.

3. Hearnshaw SA, Logan RF, Lowe D, Travis SP, Murphy MF, Palmer KR. Use of endoscopy for management of acute upper gastrointestinal bleeding in the UK: results of a nationwide audit. Gut 2010; 59:1022-1029. 
4. Sanders D.S. Carter M.J. et al. Prognosis following Upper Gastrointestinal Bleeding Prospective Validation of the Rockall Risk Scoring System for Upper GI Hemorrhage in Subgroups of Patients With Varices and Peptic Ulcers. Am J Gastroenterol 2002;97:630-635.

5. Konstantinos C. Thomopoulosa, Konstantinos A, et al. Changes in aetiology and clinical outcome of acute upper gastrointestinal bleeding during the last 15 years Eur J Gastroenterol Hepatol 2004, 16:177-182

6. Scleisenger and Fordtran's Gastrointestinal and Liver Disease. Pathophysiology/ Diagnosis/Management, $9^{\text {th }}$ Edition, Volume 1.

7. Greenwald DA. Aging, the gastrointestinal tract, and risk of acid-related disease. Am J Med 2004; 117 Suppl 5A: 8S-13S.

8. Cooper BT, Weston CF, Neumann CS. Acute upper gastrointestinal haemorrhage in patients aged 80 years or more. QJ Med 1988; 68: 765-774.

9. Nankhonya JM, Datta-Chaudhuri ML, Bhan GL. Acute upper gastrointestinal hemorrhage in older people: a prospective study in two neighboring districts. J Am Geriatr Soc 1997; 45: 752-754.

10. Segal WN, Cello JP. Hemorrhage in the upper gastrointestinal tract in the older patient. Am J Gastroenterol 1997; 92: 42-46.

11. Charatcharoenwitthaya $\mathrm{P}$, Pausawasdi, et al. Characteristics and outcomes of acute upper gastrointestinal bleeding after therapeutic endoscopy in the elderly. World $\mathbf{J}$ Gastroenterol 2011; 17(32): 3724-3732

12. Blatchford O, Murray WR, Blatchford M. A risk score to predict need for treatment for

How to cite this article:

Seena Sankar, Shruthi Kulkarni, Anu Desai. (2017). Etiology, risk factors and outcome of acute non-variceal bleed in hospitalised patients - a cross sectional study. Int. J. Curr. Res. Med. Sci. 3(8): 71-77.

DOI: http://dx.doi.org/10.22192/ijcrms.2017.03.08.012 upper-gastrointestinal haemorrhage. Lancet. 2000;356:1318-1321.

13. de Franchis R. Updating consensus in portal hypertension: report of the Baveno III Consensus Workshop on definitions, methodology and therapeutic strategies in portal hypertension. J Hepatol 2000; 33:84652.

14. Gado AS, Ebeid BA. Clinical outcome of acute upper gastrointestinal bleeding among patients admitted to a government hospital in Egypt. Saudi J Gastroenterol 2012; 18:34-9.

15. Lahiffa C, Shieldsa W, Cretua I. Upper gastrointestinal bleeding: predictors of risk in a mixed patient group including variceal and non-variceal haemorrhage. European Journal of Gastroenterology \& Hepatology 2012, 24:149-154.

16. Castro V, Gallagher PJ, Clements CC, et al. Incident user cohort study of risk for gastrointestinal bleed and stroke in individuals with major depressive disorder treated with antidepressants. BMJ Open 2012; 2:e00544. Doi: 10.1136/bmjopen-2011-000544.

17. Colin John Crooks, Joe West, and Timothy Richard Card. Co-morbidities Affect Risk of Non-variceal Upper Gastrointestinal Bleeding. Gastroenterology. 2013 Jun; 144(7): 13841393.e2.doi: 10.1053/j.gastro.2013.02.040.

18. Minoru Tomizawa, Fuminobu Shinozaki, Rumiko Hasegawa, Yoshinori Shirai, Yasufumi Motoyoshi, Takao Sugiyama, Shigenori Yamamoto, and Naoki Ishige. Low hemoglobin levels are associated with upper gastrointestinal bleeding. Biomed Rep. 2016 Sep; 5(3): 349-352.

\begin{tabular}{|c|l|}
\hline \multicolumn{2}{|c|}{ Access this Article in Online } \\
\hline Quick Response Code & Website: \\
& Www.ijcrims.com \\
\hline
\end{tabular}

